\title{
A Cross-cultural Study of The Speech Act of Compliments in American English and Yemeni Arabic
}

\author{
Najeeb Taher Al-Mansoob1, K. S. Patil2, Yasser Mohammed Alrefaee ${ }^{3}$ \\ ${ }^{1} B A M$ University, India. E-mail: najeebium@gmail.com \\ ${ }^{2}$ Siddharth Arts, Com. E Sci. College, Jafrabad Dist., India. Email: kailas.patil9687@gmail.com \\ ${ }^{3}$ Albaydha University, Yemen.Email: yasser.alrefaee@gmail.com
}

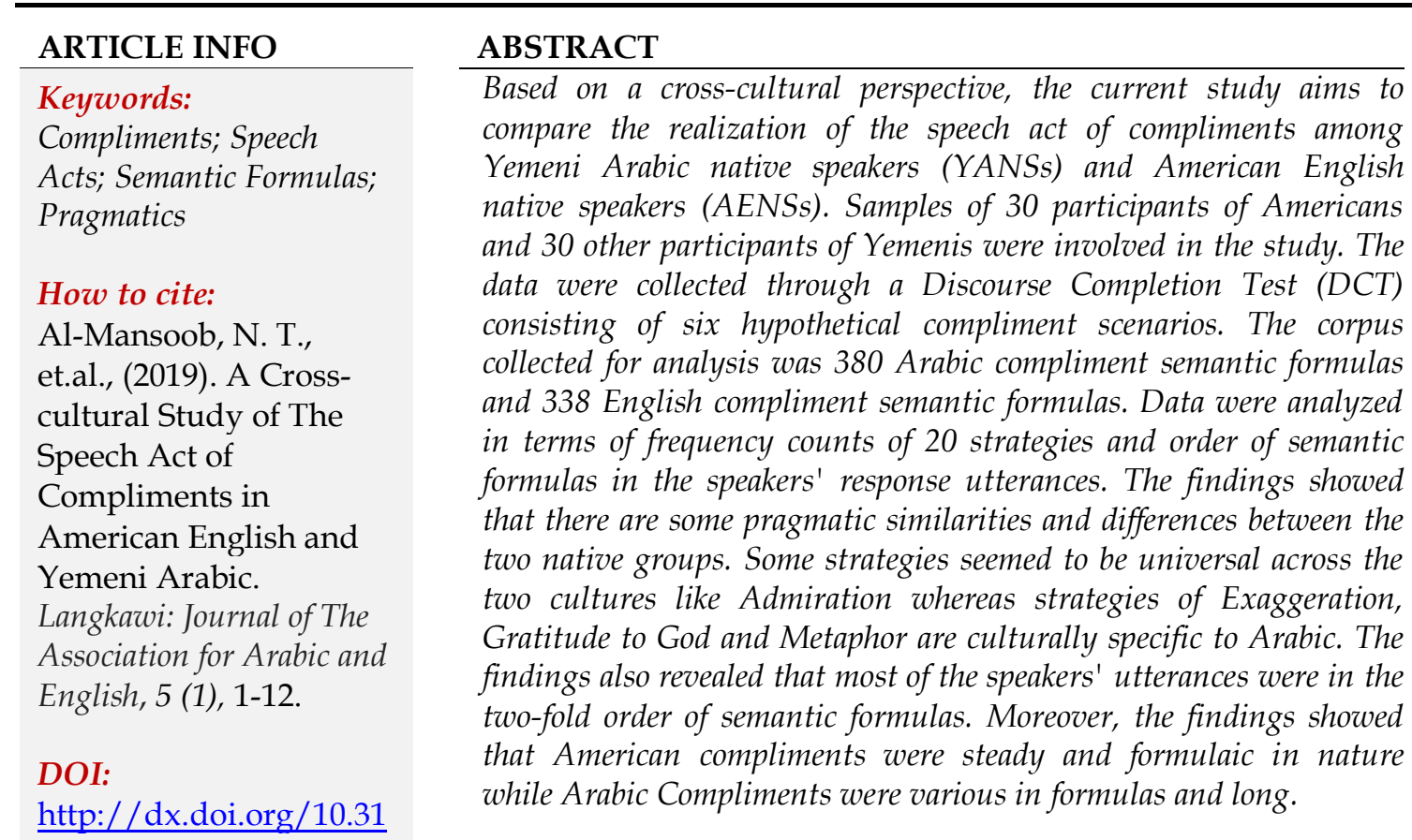

\section{Introduction}

A language is considered as a means of communication that has its own specific cultural and linguistic features. It is such an identity to its speakers. It is a must for those speakers to grasp all the sociocultural and linguistic norms dedicated by their system of communication so as to make a living and manage their local adaptation in their speech communities. But, does this fact still work today where the globe is turned to be a small village linked and shrunk by the virtue of technology!? The answer is taken for granted that diversities of world cultures, religions, traditions and beliefs play a vital role in manifesting the politeness norms of the world communities. They are considered as rigid barriers that still result in creating problems in the process of cross-cultural communication. The cultural backgrounds greatly shape the way people react and interact with each other for a "different culture holds different cultural values and beliefs, which are reflected in the use of language and how people communicate" (Alsohaibani, 2017, p.3). Consequently, such diversities in the scope of Interlanguage Pragmatic (IL) could be major causes for cross cultural communication breakdowns among L2 leaners when coming to 
socialize with L2 native interlocutors. Takahashi (1996) stated that "inter-cultural miscommunication is often caused by learner's falling down on their L1 sociocultural norms and conventions in realizing the speech acts in a target language" (p. 189).

During the previous four decades, the existence of cross-linguistic influences stimulates scholars to conduct studies across languages and cultures. There has been a great consensus among them that conducting studies across languages and cultures would ease language learning across borders and tackle any causes for possible communication breakdowns across speakers of different linguistic backgrounds (Meier, 2010; Al-Mansoob and Alrefaee, 2018; Alrefaee, 2018). Some scholars dedicate their studies for intra-lingual analysis of speech acts, the acts of getting things done by words, as to come up with what is special and particular about a language as Qanbar (2012) studied the Complimenting behavior of Yemenis. In the other hand, others conducted studies in the realizations of speech acts across two or more languages approaching the specificity and universality of speech acts across different languages. However, the claim that speech acts whether operate under some universal pragmatic norms or dedicated by a set of sociocultural principles has been highly controversial. For instance, Fraser (1985) in his study of the speech act of request across languages concluded that speech act realization is shaped by some universal pragmatic principles while Weizbicka (1985) reported that the realization of speech acts varies greatly form culture to culture. Therefore, the current study contrasts Yemenis to Americans with respect to the realization of the speech act of offering compliments so as to approach the notion of politeness and provide an evident whether these particular aspects of this speech act are specific or universal across the two cultures.

\subsection{Statement of The Problem}

The divergence of world cultures in general and the differences across languages in particular lay the ground to stimulate contrastive analysis in the way native speakers realize speech acts. As to be dedicated by cultures, the variation of speech acts across languages can be a matter of concern for both linguists and pragmatists. Speakers have to be aware of all the particularities of the speech community and keep them into their consideration when addressing other interlocutors. Being pragmatically incompetent results in risking the harmony and bonds of intimate relations between self and others and waste the efforts dedicated for the delivery of messages and establishing rapport in the process of communication (Thomas, 1983). Wolfson (1981) highlighted that "speech acts differ cross-culturally not only in the way they are realized but also in their distribution, their frequency of occurrence, and in the functions they serve" (p.123). Illocutionary force of the speech act uttered is highly dedicated by the politeness norms of the speech community culture. Ghazzoul (2019) proved that Arabic native speakers differ greatly to English native speakers in their speech as realization as the Arabic culture greatly govern the level of politeness in the Arab world. Moreover, he stated that "Arabs and English illocutionary acts differ not only in their functions, but also in their degree of politeness and committing oneself to it" (p.225). As for the speech act of compliments, it is also considered by researchers that as "a kind of culture- 
bound matter which is directly pertinent to the culture in which one has been nurtured" (Shahsavari, Alimohammadi and Rasekh,2014: 1745). It is expected that Yemenis and Americans violate the socio-cultural rules of speaking of each other if the two cultures greatly vary in the realization of compliments and they lack L2 pragmatic competence. Therefore, based on a cross cultural scale, this paper examines the pragmatic similarities and differences in the realizations of the complimenting speech act across the native speakers of Arabic and English.

\subsection{Questions of The Study}

This study attempts to find answers for the following questions: a) What are the pragmatic similarities and differences in the realization of the speech act of compliments between Yemeni Arabic native speakers (YANSs) and American English native speakers (AENSs)?; and b) What are the most frequently used compliment strategies among Americans and Yemenis?

\subsection{Significance of The Study}

This study tackles the pragmatic similarities and differences between Arabic and English with specific reference to Yemenis and Americans. It is hoped to facilitate the intercultural communication between the two target communities as it seeks to provide clearer insights of some aspects of their cultural perspectives. It is anticipated to push curriculum designers to highly concern such possible diversities and cultural gabs in their pedagogical plans so as to implement more authentic contents for second language learning. This study is also hoped to lay a better theoretical approach of the specificity and/or universality of speech acts across world languages. The data can also be used as baseline for further interlanguage studies. Moreover, the study is expected to make a contribution not only to the second language pedagogy but also the growing research stream of cross cultural pragmatics.

\subsection{Theoretical Background}

As this cross-cultural study makes a comparative investigation of the speech act of compliments, this section is dedicated to the theoretical framework. Pragmatics has been a growing scope of research interest among both psychologists and linguists as it studies the relationship between language forms and their contextual meanings. Taking a modern definition of pragmatics, Murry (2010) stated that pragmatics is "an understanding of the relationship between form and context that enables us, accurately and appropriately, to express and interpret intended meaning" (p.293). Therefore, there has been a consensus among scholars of language pedagogy that speakers of a language should be not only linguistically competent but also pragmatically competent so as to react effectively and decode the intention of the interlocutors regardless whether the target language is a mother tongue or a foreign language.

Like intra-pragmatics studies, which concern the study of the role of culture in the context and the contextual meaning of utterances toward native language, crosscultural pragmatics (CCP) emerged as a very crucial scope in the studies of pragmatics. It is concerned with the "study of different expectations among different communities regarding how meaning is constructed" (Yule, 1996, p.87). There has been a great shift to $\mathrm{CCP}$ so as to shed light into the boundaries across world 
cultures, outline the universality and specificity of speech acts (such as: refusal, requests, complains, apologies and so on) across world languages and contrast the politeness norms worldwide. Such research motives are highly adopted by second language acquisition (SLA) scholars taking into consideration that native culture diversity can be the most influential source of cross-cultural miscommunication. Yoosefvand and Rasekh (2014), for instance, proved that "successful communication in a target language requires not only the knowledge of grammar and vocabulary but also pragmatic competence and knowledge about the culture of the target language" (p.44). In this respect, pragmatic failure across languages can result in a total communication breakdown as it is seemed to be more detrimental and crucial than linguistic errors.

Politeness, as a notion stands for the speakers' self image, played a vital role in paving the ground and establishing the theoretical foundation of cross-cultural pragmatics. Pragmatics research in the scope of politeness nearly emerged in the late 1970s. Perhaps one of the most influential theories in this field was that of Brown \& Levinson (1987). Politeness centers around the speakers' intention to mitigate the face threatening acts toward the interlocutor involved in the communicating process. In this politeness theory, Brown \& Levinson classified human politeness behavior into four strategies: the bold on strategy, the off-record strategy, the positive politeness strategy and the negative politeness strategy. For them, positive face stands for the speaker's need to be approved while negative face is represented in his desire to be free from imposition.

Regarding the speech act of compliments, it is almost restricted to everyday speech situation. As a result, a great deal of cross-cultural pragmatic studies has been conducted so as to highlight the norms and politeness principles that are restricted to the realization of the speech act of compliments. Holmes (1986) defined the speech act of compliment as that act "which explicitly or implicitly attributes credit to someone other than the speaker, usually the person addressed, for some 'good' (possessions, characteristic, skills, etc." (p.485). The scope of research of cross-cultural pragmatics that investigates into the speech act realization of complements has been widely approached. More importantly, the rest of this review is briefly dedicated to some major compliment studies.

Nelson, El-Bakary and Al-Batal (1993) conducted a so popular study in the relegalization of the speech act of compliment among Egyptians and Americans. They used interviews as the data gathering tool. The data was analyzed in terms of frequency, participants' status and relationship and gender differences. Major findings indicates that Egyptians tend to use less compliments than Americans. And Americans more frequently compliment each other in skills and work while Egyptians showed higher tendencies for personality traits. Intachakra (2004) conducted a crosscultural study in the speech act of thanks as a complimenting behavior between the native speakers of Thai and the native speakers of English. Data was collected via natural observation. He concluded that the participants' thanking strategies vary greatly due to the specificity of this act to culture. More importantly English natives showed a more tendency towards using direct thanking strategies than Thai natives. Yu (2005) investigated the pragmatic similarities and difference between Chinese and Americans using observations. He analyzed the 
sociocultural features of compliments and concluded that culture played a vital role in the complimenting behavior of both Chinese and Americans. Americans in this respect used compliments as to show friendliness while Chinese tended to use them less frequently. Regarding the Yemeni context, Qanbar (2012) conducted an intralingual wide-range empirical study of the complimenting behavior of Yemenis. She collected 400 Arabic compliments from 20 college students via an ethnographic method. One of the major findings of her study was that the complimenting behavior of Yemeni native speakers is formulaic as $65.75 \%$ of the corpus collected fall into specific syntactic patterns.

\section{Methods}

\subsection{Participants and Sampling Procedures}

This cross-cultural study is conducted to contrast YANSs to AENSs. Participants targeted in the study were 30 Yemenis and 30 Americans. They were selected randomly out of their native communities. Gender differences factor was not taken into account in the analysis of the data, but the data gathering tool was equally administered among males and females so as to hopefully vary the responses and get more authentic data. The participants representing Yemenis were selected randomly from Sana'a University which is located in the capital city of Yemen. Americans were randomly selected from the students' lists of Southern Illinois University, Carbondale, United States of America.

\subsection{Data Collection Procedures}

Data were collected by means of a Discourse Completion Test (DCT) consisting of six hypothetical situations. DCTs according to Kasper (1992) "are written questioners including a number of brief descriptions, followed by a short dialog with an empty slot for the speech act under study (p.221). The hypothetical scenarios of the DCT used in the study cover daily used compliment topics of appearance, possession, ability and personality traits. Therefore, this tool was designed to elicit compliment utterances and validated by experts. It was also pilottested on five native speakers of Arabs and Americans as to be culturally appropriate for collecting related data. It was in two versions in both Arabic and English. After setting the scene of the sampling procedures, the Arabic version of the DCT was administered among 30 native Arabic speakers at Sana'a University by the researcher himself and the English version was administered in Southern Illinois University by a Yemeni scholar studying in the US.

\subsection{Data Analysis Procedures}

Since the study centers around cross-cultural pragmatics, data were codified functionally. The researcher used a modified scheme based on Enssaif's (2005) coding scheme of compliments. This taxonomy consists of the following strategies that are related to the complimenting speech act as shown in the table: 
Table (1): Data Analysing Taxonomy

1- Admiration

\section{Strategies}

\section{Definitions}

Explicitly using verbs as: like/love or inserting positive adjectives such: pretty, great, nice ...etc. (e.g., It is nice; I like it.)

2-Encouragement Stimulating the complimentee to persuade more achievements. (e.g., Go ahead!)

3-Approval Positively evaluating what has been achieved. (e.g., Well done!)

4-Wish Making a wish for the complimentee. (e.g., I wish you a
happy life!)

5-Surprise

Expressing a surprise on the part of the complimentee. (e.g., I can't believe it!)

6-Exclamation Implicitly making an admiration via an exclamatory utterance. (e.g., What a beautiful hairstyle!)

7-Congratulation Explicitly congratulating the addressee for some achievement or traits. (e.g., Congratulations!)

8-Noticed change Explicitly expressing the change on the part of the addressee. (e.g., You look different!)

9-Metaphor Praising the complimentee via an unordinary description. (e.g., You are a real star!)

10-Invocation Wishing the complimentee by the name of God. (e.g., Allah bless you!)

11-Comparison Explicitly comparing some relevant affairs. (e.g., Yours is better!)

12-Exaggeration Admiring the complimentee's affairs via exaggeration. (e.g., She has a magic hand!)

13-Questioning Making an interrogative utterance as a compliment. (e.g., What have you done to remain so young?!)

14-Gratitude to God Expressing gratitude to God for the complimentee's achievement. (e.g., Thanks God!)

15-Appreciation Expressing a direct gratitude to the complimentee for an achievement. (e.g., I am grateful for you!)

16-Bride Explicitly expressing pride of the addressee. (e.g., I am proud of you!)

17-Happiness Explicitly expressing happiness of the addressee's affairs. (e.g., Happy for that!)

18-Expectation Showing expectation of what has been achieved by the complimentee. (e.g., I expect you would get it!)

19-Advice Giving a piece of advice for the complimentee. (e.g., You should be very happy about that!)

20-Silence Leaving the scenarios blank without giving a compliment. 
Therefore, the collected utterances were codified into their corresponding semantic formulas. The semantic formulas are the strategies used in response to DCT scenarios. A semantic formula for Cohen (1996) is "a word, phrase or sentence that meets a particular semantic criterion or strategy; any one or more of these can be used to perform the act in question" (p.265). The corpus of 180 situations of American English native speakers was compared to the corpus of 180 situations of Yemeni Arabic native speakers it terms of the frequency counts of the semantic formulas and the orders of the semantic formulas utilized in the speakers' response. The comparison means and the layout of the graph and frequency counts of strategies was done via Excel program.

\section{Results and discussion}

Taking into account the two-fold focus of this cross-cultural pragmatic study, the section is set so as to answer the two questions of the study. First, it presents the frequency counts and the percentages of the used strategies of the speech act of compliments for both Yemenis and Americans. Then, it further presents the orders of semantics formulas used in the speakers' utterances of the two target groups.

\subsection{The Overall Used Strategies}

To pinpoint the most used strategies by each Arabs and Americans, a brief outline of the frequency counts of all the used semantic formulas is needed to be highlighted. Therefore, the table below shows an overall contrastive presentation of the 20 strategies used by AENSs and YANSs.

Table (2): The Frequency Counts of the Overall Used Strategies for YANSs \& AENSs

\begin{tabular}{lllll}
\hline \multirow{2}{*}{ Compliment strategies } & \multicolumn{2}{l}{ YANSs } & \multicolumn{2}{l}{ AENSs } \\
\cline { 2 - 5 } & $\mathrm{F}$ & $\%$ & $\mathrm{~F}$ & $\%$ \\
\hline Admiration & 84 & $22.1 \%$ & 116 & $34.3 \%$ \\
\hline Advice & 6 & $1.6 \%$ & 6 & $1.8 \%$ \\
\hline Appreciation & 10 & $2.6 \%$ & 3 & $0.9 \%$ \\
\hline Approval & 9 & $2.4 \%$ & 23 & $6.8 \%$ \\
\hline Bride & 4 & $1 \%$ & 6 & $1.8 \%$ \\
\hline Comparison & 5 & $1.3 \%$ & 2 & $0.6 \%$ \\
\hline Congratulation & 36 & $9.5 \%$ & 41 & $12.1 \%$ \\
\hline Encouragement & 4 & $1 \%$ & 3 & $0.9 \%$ \\
\hline Exaggeration & 10 & $2.6 \%$ & 0 & $0 \%$ \\
\hline Exclamation & 29 & $7.6 \%$ & 3 & $0.9 \%$ \\
\hline Expectation & 8 & $2.1 \%$ & 16 & $4.7 \%$ \\
\hline Gratitude To God & 1 & $0.7 \%$ & 0 & $0 \%$ \\
\hline Happiness & 6 & $1.6 \%$ & 31 & $9.2 \%$ \\
\hline Invocation & 38 & $10 \%$ & 2 & $0.6 \%$ \\
\hline Metaphor & 9 & $2.4 \%$ & 0 & $0 \%$ \\
\hline Noticed Change & 31 & $8.2 \%$ & 18 & $5.3 \%$ \\
\hline Question & 14 & $3.7 \%$ & 38 & $11.2 \%$ \\
\hline Silence & 4 & $1 \%$ & 2 & $0.6 \%$ \\
\hline Surprise & 30 & $7.9 \%$ & 14 & $4.1 \%$ \\
\hline Wish & 42 & $11 \%$ & 14 & $4.1 \%$ \\
\hline & -7 & & & \\
\hline
\end{tabular}


As displayed in Table (2) above, YANSs and AENSs assimilate each other in the top most frequently used compliment strategy which is 'Admiration'. There also appeared a huge variation in the use of this strategy in that Yemenis used it for 84 times in their 380 response utterances at the rate of $22 \%$ while Americans tended to use it for 116 with the rate of $34.4 \%$ of the total 338 response utterances. Arabs mostly used this semantic formula in the utterance of (نك تبدو وسيما)/trans. You look handsome!) while Americans used it mostly in the utterance of (You have a nice jacket!). The two groups are seemed to be similar in this the respect of the most used strategy regardless the differences in the frequency counts which can be due the variations of the percentages of the overall used strategies.

As for the second mostly utilized compliment strategies among the participants, YANSs tended to use Wish strategy 42 times of the total 380 response utterances with the rate of $11 \%$. Their mostly used formula in this strategy was represented in the utterance of ( أتمنى للك حياة سعيدة trans. I wish you a happy life ahead!). On other side, AENSs behaved differently in the realization of the second mostly used compliment strategy. They tended to utilize Congratulation 41 times in their utterances as saying (Congratulations!) at the percentage of $21 \%$ of the overall formulas. Wish strategy, however, is for Americans one of the least utilized semantic formulas and Congratulation scored the forth mostly used strategy for Arabs.

It is also clear that Invocation is the third mostly utilized strategy for YANSs. The frequency count for this strategy is 30 at the percentage of $10 \%$. YANSs used invocations with the name of God as in (الله يحميه trans. May Allah protect him from evil doers!). This might be because that YANSs are religious in nature unlike Americans who uttered this strategy for only two times in their response utterances. AENSs showed a different tendency in the use of third mostly used strategies. They utilized Question strategy for 38 times in their utterances scoring the percentage of $11.2 \%$. They greatly made compliment questions for the complimentee as saying (Did you get it cut?!) while YANSs used Question formulas for only 14 times in their overall used strategies.

As for the forth used strategy among Americans, they expressed their happiness towards the complimentee's achievements for 31 times whereas Yemenis utilized Happiness for only 6 times. This variation can be due to the diversity of the two target cultures. Utterances such as (تبدو مختلف trans. You look completely different) represented the fifth most used strategy at the frequency count of 31 with the rate of $8 \%$ for YANSs. This semantic formula stands for the Noticed Change strategy. AENSs, on the other hand, utilized this strategy for only 18 times with the rate of $5.3 \%$ of the total used formulas.

The difference across the two groups is greatly seemed in the realization of this speech act. Surprise strategy is still one the mostly used formulas among YANSs. It is the sixth most used strategy in that they utilized it 30 times as in saying ( لا اصدق ذللك trans. I can't believe it!). Unlike YANSs, AENSs used surprise utterances for only $4 \%$ of their total used semantic formulas. The strategies of Appreciation, Approval, Exaggeration, Exclamation and Expectation as displayed in the table above varied greatly across to the two native groups, but they are relatively less important since their relevant frequencies are secondary. Interestingly, Advice semantic formulas were used for six times of the response utterances of each of the two groups. 
Moreover, the strategies of Bride, Comparison, Encouragement, Gratitude to God, Metaphor and Silence represent the least utilized formulas for the two groups. This can be due to the claim that some speech act norms are still universal across the world languages.

\subsection{The Order of Semantic Formulas}

Each participant of the two groups responded to six hypothetical situations. What is being clearly revealed is that most of the responses were not single utterances. Those responses vary in length and order of semantic formulas. For instance, an AENS participant paid a compliment to an old flatmate who had lost weight as saying: "You had lost a lot of weight! Congrats! You look adorable!" This three-fold answer corresponds to the formulas of (Noticed Change+ Congratulation+ Admiration). As a result, such longer responses pushed the researcher to make a further comparison between Yemenis and Americans at the order of semantic formulas in the response utterances. The following graph reveals the lengths of the speakers' responses across the overall 180 situations.

Graph (1): The Length of the Compliment Utterances for both YANSs \& AENSs

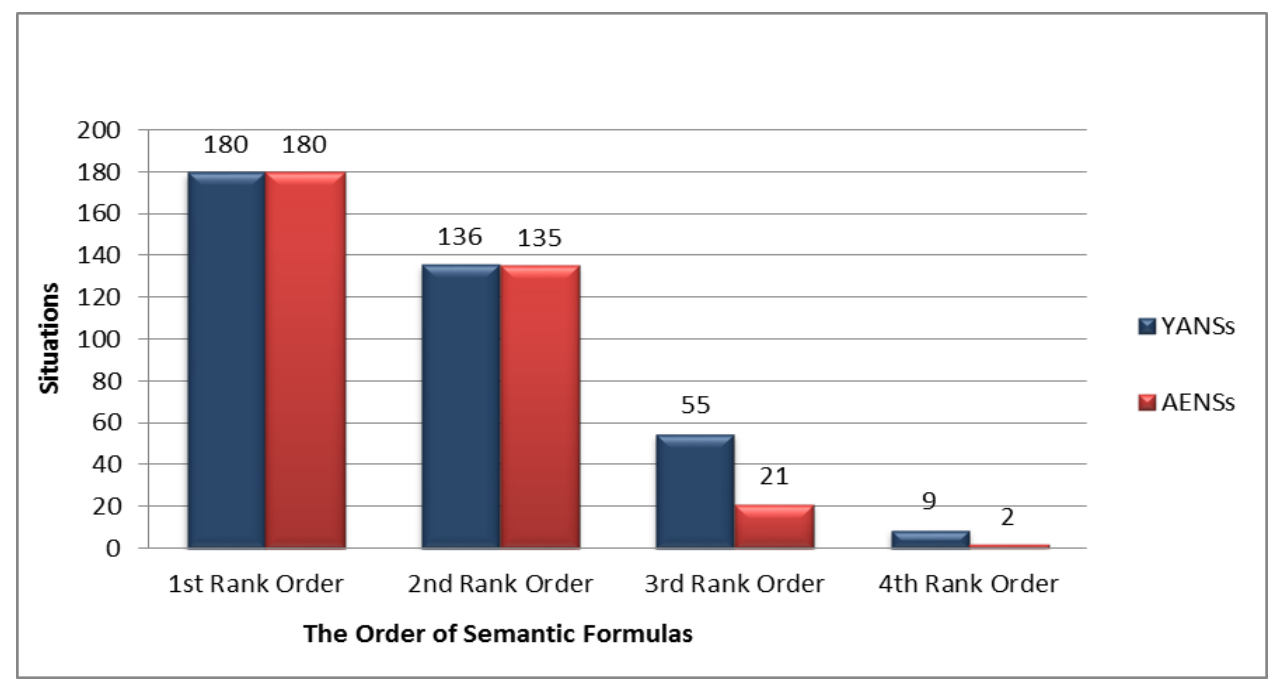

As shown in Graph (1) above, there are some similarities and differences in the lengths of utterances between YENSs and AENSs. Most of the response utterances of the two groups appear not to exceed two-fold formulas whereas less than forth of the responses seemed to be of three or four formulas. Out of Graph (1) above, there can be a more detailed illustration for the rank orders of formulas and their percentages across the 180 response situations. It can be as shown in table (3) below:

Table (3): Length of Semantic Formulas of The Response Utterances

\begin{tabular}{|c|c|c|}
\hline Length of response utterance & YANSs & AENSs \\
\hline One-fold semantic formulas & $44(24.4 \%)$ & $45(25 \%)$ \\
\hline Two-fold semantic formulas & $81(45 \%)$ & $114(63.3 \%)$ \\
\hline Three-fold semantic formulas & $46(25.5 \%)$ & $19(10.5 \%)$ \\
\hline Four-fold semantic formulas & $9 \quad(5 \%)$ & $2 \quad(1 \%)$ \\
\hline
\end{tabular}


Form Graph (1) and Table (3) above, it is shown that forth of the response utterances of both YANSs and AENSs are mono-strategic utterances. YANSs responded to 44 out of 180 situations in single formulas. One of the most response utterances that are one-fold utterances is illustrated in their Admiration utterances as saying (تبدو مختلف trans. You look different!). Similarly AENSs responded to 45 situations of their 180 responses in single formulas. This can be exemplified in their use of Admiration as saying (I like your jacket!). interestingly, the mostly used order of semantic formulas for Americans is the two-fold order. They tended to respond in combinations such as: Admiration+ Question, Surprise+ Expectations, Happiness+ Questions and Congratulation+ Admiration. To set it clearer, two fold-utterances as in saying (I really like your hair! Did you get it cut?) were used 114 times. This rates $63 \%$ out of 180 situations. In the other side, YANSs used the tow-fold utterances more than any other combination of formulas. For them, utterances such as in saying (rans. I like your style! You look completely different!) used 81 times with the percentage of $45 \%$ of the total multifold response utterances. The similarity in the use of two-fold formulas between Arabs and Americans seemed to be strange in that Americans tended to use it more than Yemenis.

Graph (1) and Table (3) also reveal that Yemenis used the four-fold formulas 46 times in their responses. For instance a Yemeni participant responded to the haircut situation as اعجبتني، تبدو رائع، انك حقا ذواق) trans. I liked you! You look smart! You really have a good taste!). This long response stands for (Admiration+ Admiration+ Admiration). On the other side, Americans tended to use three-fold formulas in their responses only 19 times which seemed to be different to that of Yemenis. As for the forth-fold formulas, American only used it for two times while Yemenis utilized it for 9 times. It is clear that American response tended to be steady and short while Yemenis used longer responses. This can be due to the perception among Yemenis that longer expressions show more politeness. This claim was also supported by Nelson, El-Bakary and Al-Batal (1993) in their study of the complimenting behavior of both Americans and Egyptians. They reported that Egyptian Arabic speakers considered longer compliments as a mark of more sincerity.

\section{Conclusion}

The findings of the study revealed that the mostly used compliment strategies for YANSs are Admiration, Wish, Invocation, Congratulation, Noticed Change and Surprise and for AENSs are only Admiration, Congratulation, Question and Happiness. The findings also indicate there is a set of similarities and differences between YANSs and AENSs in the ways they realize the speech act of compliments. They showed a big similarity in the use of Admiration which is the mostly used compliment strategy. They further assimilated each other in showing higher tendencies of using two-fold utterances. Both Yemenis and Americans tended to utilize formulaic utterances, but Yemenis paid more compliments than Americans. However, there are still two striking results about such similarities. First, the frequency counts of the mostly used compliment strategy, which is Admiration, greatly vary across the two native groups. Second, the most used length of utterances for AENSs and YANSs, which is the two-fold rank order of strategies, still varies in frequency i.e. AENSs used this rank order 114 times while YANSs utilized it for only 
81 times of their responses. There are also some other important differences shown between the two native groups. Americans' responses mostly tended to be short and restricted to limited number of strategies while Yemenis showed more tendency of using longer response utterances with higher number of strategies. The findings further revealed that the two native groups behaved differently with respect to the less frequently used strategies which are Appreciation, Approval, Bride, Comparison, Encouragement, Expectation, and Silence. Furthermore, the findings indicate that the strategies of Metaphor, Gratitude to God and Exaggeration are culturally restricted to Yemeni Arabic.

\section{References}

Al-Mansoob, N. T. and Alrefaee, Y. M. (2018) Pragmatic Transfer of Yemeni EFL Learners: An Interlanguage Pragmatic Study of Yemenis and Americans. Saarbrücken, Deutschland: LAP LAMBERT Academic Publishing.

Alrefaee, Y. M. (2018) Pragmatic Transfer and Its Relation to Proficiency. Saarbrücken, Deutschland: LAP LAMBERT Academic Publishing

Alsohaibani, A. (2017). Influence of Religion on Language Use: a sociopragmatic study on the influence of religion on speech acts performance. (Unpublished doctoral thesis). University of East Anglia. England.

Brown, P., \& Levinson, S. (1987). Politeness: Some Universals in Language Usage. Cambridge University Press, Cambridge.

Cohen, A., (1996). Developing the ability to perform speech acts. Studies in Second Language Acquisition, 18, 253-267.

Enssaif, Z. (2005). Compliment behavior: Strategies and realizations in English and Arabic: A case study of female students of the English department, King Saud University. (Unpublished master's thesis). King Saud University, KSA.

Fraser, B. (1985). On the universality of speech act strategies. In S. George (Ed.), from the linguistic to the social context (pp. 43-49). Bologna, Italy: Clueb.

Ghazzoul, N. (2019). Linguistic and Pragmatic Failure of Arab Learners in Direct Polite Requests and Invitations: A Cross-cultural Study. Theory and Practice in Language Studies, 9(2), 223. https:/ / doi.org/10.17507/tpls.0902.13

Holmes, J. (1986). Compliments and compliment responses in New Zealand English. Anthropological Linguistics, 28(4), 485-508.

Intachakra, S. (2004). Contrastive pragmatics and language teaching: Apologies and thanks in Englishand Thai. RELC Journal: A Journal of Language Teaching and Research, 35(1), 37-62.

Kasper, G. (1992). Pragmatic transfer. Second Language Research, 8, 203-231.

Meier, A. J. (2010). Culture and its effect on speech act performance. Speech act performance: Theoretical, empirical and methodological issues, 75-90. Amsterdam: John Benjamins.

Murray, N. (2010). Pragmatics, awareness raising, and the cooperative principle. ELT Journal 64.3, 293-301. doi: https://doi.org/10.1093/elt/ccp056. 
Nelson, G., El-Bakary, W., \& Al Batal, M. (1993). Egyptian and American compliments: A cross-cultural study. International Journal of intercultural relations, 17(3), 293-313.

Qanbar, N. (2012). Compliments in the Yemeni society: A Sociolinguistic Perspective. GEMA Online ${ }^{\circledR}$ Journal of Language Studies. 12(3), 999-1017.

Shahsavari, S., Alimohammadi, B., \& Rasekh, A. E. (2014). Compliment Responses: A Comparative Study of Native English Speakers and Iranian L2 Speakers. Procedia - Social and Behavioral Sciences, 98, 1744-1753. https://doi.org/10.1016/j.sbspro.2014.03.602

Takahashi, S. (1996). Pragmatic transferability. Studies in Second Language Acquisition, 18(2), 189-223.

Thomas, J. (1983). Cross-cultural pragmatic failure. Applied Linguistics, 4, 91-112.

$\mathrm{Yu}, \mathrm{M}$. C. (2005). Sociolinguistic competence in the complimenting act of native Chinese \& American English speakers: A mirror of cultural value. Language \& Speech, 48(1), 91-119.

Yule, G. (1996). Pragmatics. UK: Oxford University press.

Wierzbicka, A. (1985). Different cultures, different languages, different speech acts. Journal of Pragmatics 9, 145- 178.

Wolfson, N. (1981). Compliments in cross-cultural perspective. TESOL Quarterly, $15(2), 117-24$.

Yoosefvand, A. and Rasekh, A. E. (2014). A comparative study of Gratitude Speech Act between Persian and English Speakers. Journal of Applied Linguistics and Language Research, 1(2), 44-61. 